\title{
Article
}

\section{Structure of Thermal Drilling Joints}

\author{
Lydia Sobotova ${ }^{1 *}$, Miroslav Badida ${ }^{1}$ and Alica Maslejova ${ }^{2}$ \\ 1 Technical University of Kosice, Faculty of Mechanical Engineering, Letna 9, 04001 Kosice, Slovakia; \\ lydia.sobotova@tuke.sk, miroslav.badida@tuke.sk \\ 2 U. S. Steel Kosice, s.r.o., 04454 Kosice, Slovakia; AMaslejova@sk.uss.com \\ * Correspondence: lydia.sobotova@tuke.sk; Tel.: +421 556022793 (L.S.)
}

\begin{abstract}
The contribution deals with the joining of various types of materials by technology of thermal drilling. In various branches of industries, also in the automotive industry must be joining operations, service, repairing, substitution or protection workpieces, components with various types of materials. Equally, the important role as joint, is also used material, and a product preparation by assembly and disassembly operations. By utilization of new friction hybrid joining technologies we can shortage the production time, provide automation in operations, increase the quality of joints, spare of economical expenses and also we can protect the environment. In this paper authors have investigated the effect of friction drilling on the tested material, aluminium alloy $\mathrm{AlMgSi}$, which was used for material testing. The created joints were evaluated visually and by microscopy methods. The errors of tested joining were documented and described, too. This contribution was made with cooperation of Technical University of Kosice and with U. S. Steel Kosice, s.r.o.
\end{abstract}

Keywords: thermal drilling; material; visual evaluation; macrostructure; microstructure

\section{Introduction}

The automotive sector along with other industrial sectors will rapidly integrate new advantageous manufacturing processes. With the development and using of new materials arise the requirement of special joins of materials in the production of automobiles.

Therefore, the exist theory of "Design for Assembly (DfA)" defined as the process, by which a product is designed to be easily assembled. Such design simplifications are accomplished through reducing the number of operations required to assemble the product, improving the handling of each component, and/or modifying the required operations (insertion, joining, etc.). The first technique is a component elimination procedure, the second technique is a component combination analysis, and the third technique establishes a logical approach for revealing [1].

Joining is also a problem from an efficiency viewpoint. It often needs some extra material to be added to the structure (such as screws, bolts, or welding filler metal). Also it sometimes leads to local weakening of the mechanical properties of the material of the components (for example in the heat affected zone of a weld). All these aspects usually lead to the application of safety factors and thus, an increase in mass needed to fulfil a given structural function. In general, the number of joining operations has to be minimized in order to decrease the overall cost of a product and spent energy. Moreover, recent trends toward recycling may lead the designer to consider disassembling as well as assembling components.

Joining requirements are important for design of joining. Four types of design issue for joining are existed:

- the geometry of the joint,

- the materials to be joined,

- the functions required from the joint,

- the joining production conditions. 
Environmental requirements are also necessary for production purposes:

- design for disassembly,

- material and energy saving,

- reuse of materials,

- recycle of materials,

- fuel-economy regulation.

Therefore, it is necessary to investigate the alternative methods of material joins in automotive industry. Form and friction drilling techniques are now promising alternatives for creating of joining that will very probably supersede conventional drilling techniques, as rapid and economic solutions for producing nut-less bolted joints [2,3].

In this context, friction drilling is fast emerging as an innovative option when joining materials with very different mechanical and chemical properties. It is as quick as drilling and may sometimes reduce the number of mechanical elements in a joint. More recently, techniques to join Fe metal and light metals in automotive applications have become a key research area. Several factors have to be considered when joining metallic alloys: differences in melting temperature, thermal expansioncontraction mismatch during joining and in service, the effects of fixtures and constraints on joining stresses, formation of brittle inter-metallic compounds during joining that may lead to brittle joints, potential for galvanic coupling and corrosion in service, and heating and cooling rate effects on the microstructure of the joint. All these factors may affect the heat input intensity and its precision control $[3,4,5]$.

Friction drilling (FD) is a clean, efficient process that can produce reliable components with similar resistant features. Mass reduction of automotive body structures is an issue for automotive builders. For instance, Audi@ uses the Flow Drill Screwing FDS® (from Swedish company EJOT) process. FSW of aluminum and steel has also been used in the manufacture of some vehicle components by Mazda@ and Honda@ $[7,8]$.

The concern of the scientific community to promote green manufacturing in almost all fields of engineering is gathering pace. In application to drilling operations, minimum quantity lubrication (MQL) techniques are worth mentioning as environmentally friendly machining alternatives [9].

The thermal drilling technology belongs to chip-less technology, so it is one possibility, how to decrease the production waste and protect the environment [10].

\section{Friction Drilling Method}

The friction (form) drilling process is a non-conventional process of generating holes, bushings and collars in used material. It is based on material removal by friction and heat generated by a rotary tool with no cutting edge [5,11,12].

Friction drilling is a metalworking process that occurs above the recrystallization temperature of the material. After the grains deform during processing, they recrystallize, which maintains an equated microstructure and prevents the metal from excessive work hardening. The heat generation is the function of surface speed, which imparts more plasticity and hence grain refinement near the boundary, speed has major effect on surface roughness. The speed increases the frictional heat causing more plasticity and hence better movement of the material resulting in lower dimensional error whereas surface roughness found to be considerably varying with the speed $[13,14,15]$. With the increase of speed from 2500-4500 RPM the surface roughness surface roughness decreases from $0.536 \mu \mathrm{m}$ to $0.341 \mu \mathrm{m}$.

Thermal mechanical finite element modeling of the friction drilling process to understand the material flow, temperature, stresses and strains which are difficult to measure experimentally has been done by $[12,15]$. This research demonstrated the application of the 3D finite element modeling 
(ABAQUS/EXPLICIT FEM) to model the large plastic strain and high temperature work-material deformation inherent in friction drilling process $[16,17]$.

Work material is subjected to the large deformation and high temperature during the friction drilling process which causes alteration in macrostructure and material properties, these findings have been reported by $[11,17,18]$. Authors in this work described that the quality of hole is affected by magnitude of friction forces and heat produced during friction drilling process which in turn depending on thermal conductivities of materials involved [19,20, 21, 22].

The friction drilling tool has two different sections: a conical surface that opens the aperture and softens the sheet material, and a cylindrical one that determines the final aperture diameter. One drawback is significant burring on exiting the hole.

The Flowdrill tool comes into contact with the material using relatively high axial pressure and rotational speed. The generated heat makes the material soft and malleable enough to be formed and perforated. As the Flowdrill indents into the material, some of the displaced material forms a collar around the upper surface of the workpiece. The rest of the material forms a bushing in the lower surface of the workpiece [20].

The sharp edges at progressions of tool from point to conical and from conical to cylindrical are rounded to protect the tool from initial wear and to increase the tool life. Small amount of parting paste is applied on tool prior to the friction drilling operation in order to prevent the material transfer from workpiece to the tool and to protect the tool from early wear [18].

The bushings, created by thermal drilling operations and following tapping operations, increase the stiffness joints of automobile parts.

The process has many advantages over traditional processes. First, there is no need for cooling. In conventional drilling processes, lubricant reduces friction and heat facilitates chip evacuation, unlike the friction-drilling technique, which is therefore defined as a clean process. Moreover, the burr can even be used to thread holes in complex and inaccessible tubular geometries. Most of the workpiece material in contact with the tool becomes part of the burr that is generated at the bottom of the part and a small portion of the material generates burrs on top [10,13, 17].

After drilling the hole, the form tapping process takes place. Threading processes are widespread in many mechanical applications, as screwable joints represent the most extensively used methods in the assembly of mechanical components. In accordance with the manufacturing process, two methods are used to generate an inner thread: either by forming or by cutting. Thread may be produced by cold forming, which involves the deformation of the raw material under cold working conditions, while in the case of cut tapping, the thread is obtained as in many other machining processes by chip removal [15, 17, 23, 24, 25]. [4, 23] demonstrated the feasibility of successively applying form drilling and tapping, in order to achieve a good joint of similar strength to conventional drilling, but simultaneously avoiding the use of nuts (and even screws) in some cases. The combination of drilling and tapping can be easily automated (approx. 10,000 threads without supervision), and it is therefore highly recommendable in applications where high productivity rates are required, as in the case of automotive applications [23].

\section{Experimental Details}

In the frame of experiments in the Department of Process and Environmental Engineering, Faculty of Mechanical Engineering, TU of Kosice, there were verified the suitability of thermal 
drilling technology for chosen $\mathrm{Al}$ alloy materials. The visual evaluation of quality of produced bushings, holes, threads at various conditions and an evaluation of macro and micro structures of tested materials were processed.

The experiments are carried on drilling machine type Flott P2 having speed range of: 450-4000 rpm., Fig. 1. Experimental works on the machine was done manually. Three speed ranges were used for experiments in intervals: $\mathrm{A} 1=1470 \mathrm{~min}^{-1}, \mathrm{~A} 2=2530-2550 \mathrm{~min}^{-1}$ and A3 = $3200-3430 \mathrm{~min}^{-1}$. The Flowdrill tool has the standard geometry viz. point, conical section, cylindrical section, shoulder and the shank. The Flowdrill drilling tools made of Tungsten Carbide in Cobalt matrix have been selected for experimentations:

- drill 1: type - Flowdrill short, diameter $\varnothing 7,3 \mathrm{~mm}$ (M8);

- drill 2: type Flowdrill short with milling cutter $\varnothing 7,3 \mathrm{~mm}(\mathrm{M} 8)$ and lubrication paste FDKS - from the Flowdrill manufacturer;

- forming tap M8, Rpm during tapping: 600- 680 min-1, lubrication oil FDKS - from the Flowdrill manufacturer.

Properties of used tool: hardness HRA: 89 - 93,5, Max. working temperature: to $900^{\circ} \mathrm{C}$.

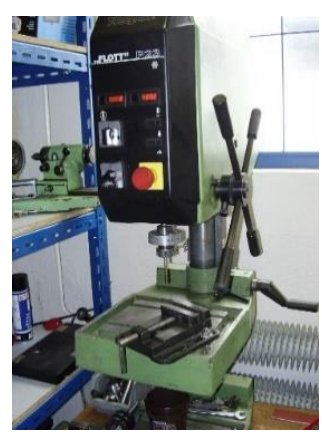

(a)

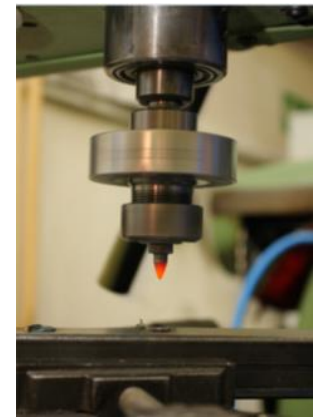

(b)

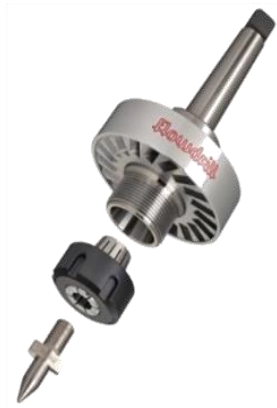

(c)

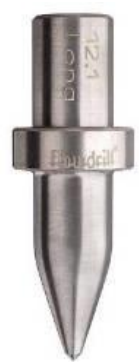

(d)

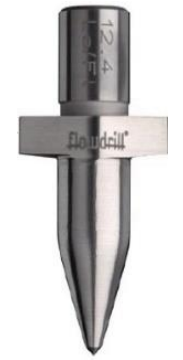

(e)

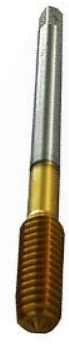

(f)

Figure 1. The used drilling machine and tools: (a) type Flott P2, (b) detail of fastened FD tool, (c) FD tool with cooling disc, (d) FD tool short, (e) FD tool short with milling cutter, (f) tapping tool.

The tested materials were placed on top of each other and were fastened in the jig, as it is shown in the Fig.2.

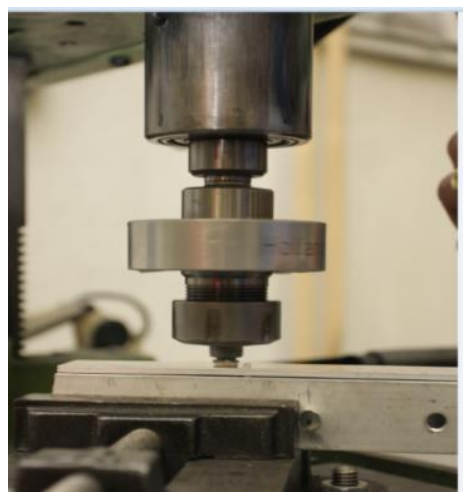

(a)

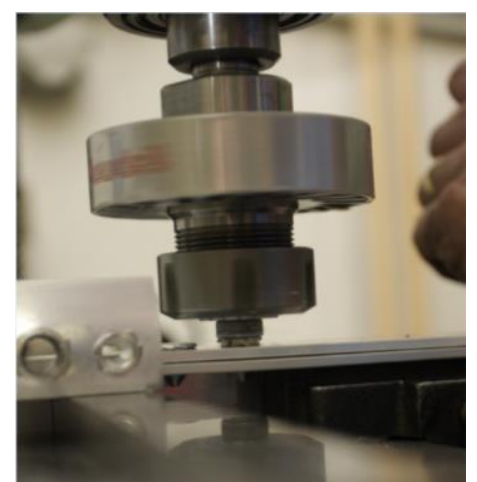

(b)

Figure 2. Fastening of the testing materials in the jig: (a) square pipe, (b) two material sheets.

The material selected for this study was Al alloy AlMgSi according to Slovak standard STN 42 4401, which had chemical composition in Table 1 and mechanical properties in the Table 2. The dimension and the type of tested materials were: the square pipe: (prism): 30x30x2 mm thickness, longitude $300 \mathrm{~mm}$. 
Table 1. Chemical elements of tested material.

\begin{tabular}{cccccc}
\hline $\begin{array}{c}\text { Chemical } \\
\text { element }\end{array}$ & Al & Fe & Cu & Si & $\begin{array}{c}\text { Other } \\
\text { elements }\end{array}$ \\
\hline $\begin{array}{c}\text { Content } \\
{[\%]}\end{array}$ & 98,8 & 0,4 & 0,2 & 0,4 & 0,2 \\
\hline
\end{tabular}

Table 2. Mechanical properties of tested material.

\begin{tabular}{ccc}
\hline Tested sample & Rm [MPa] & A80 [\%] \\
\hline AlMgSi & $120-215$ & $6-14$ \\
\hline
\end{tabular}

\subsection{Experimental Set Up}

The planned experiment consisted of two parts:

- visual evaluation of the testing samples,

- metallographic evaluation (macro and micro structures).

The materials for experimental testing had one and two layers. The aim of the visual and metallographic testing was to compare and to investigate the material behavior and deformation after creating of collar and bushing.

\subsubsection{Visual evaluation}

Visual evaluation of the experiment was done according to standard STN 038103 - "Evaluation by visual control". There were prepared the testing samples at the various testing speed and were taken photos from them. The sorted tested samples according the drilling speed are shown in the Table 3.

The shapes of created collars are different and depend on the drilling speed. Regularly split, torn collars are created at lower speeds. The higher the speed, the better the integrity and shape of the collars. Also the holes with cut collars are shown in the Table 3. 
Table 3. Visual evaluation of collars at changed speeds of tool, view from above.

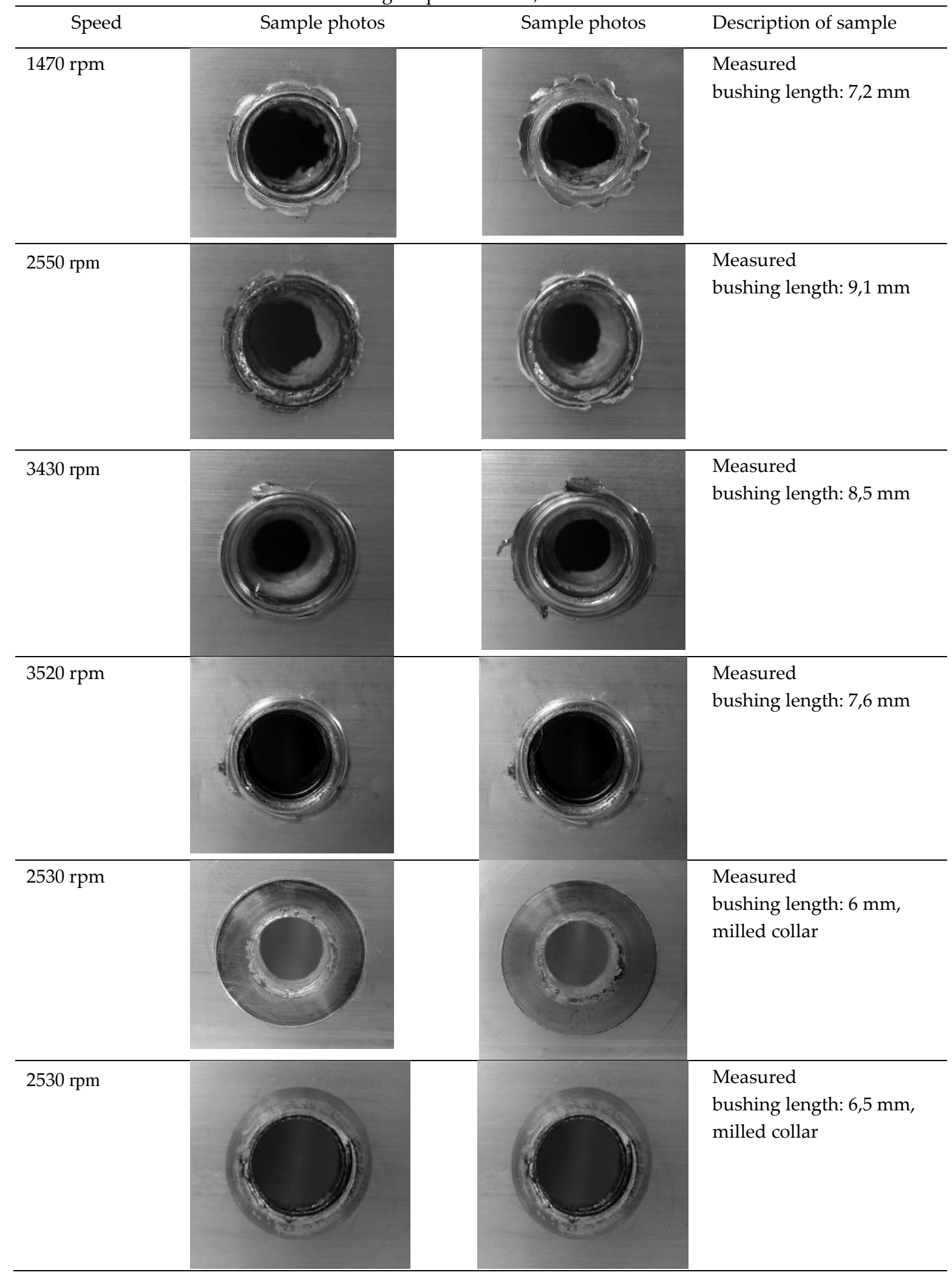

Visual assessment of created bushings and collar are presented in the Table 4 . There is shown also the bushing with tapped threads. The sealed samples are with and without collars. 
Table 4. Visual evaluation of collars and bushings from one layer of material AL alloy - Al Mg Si.

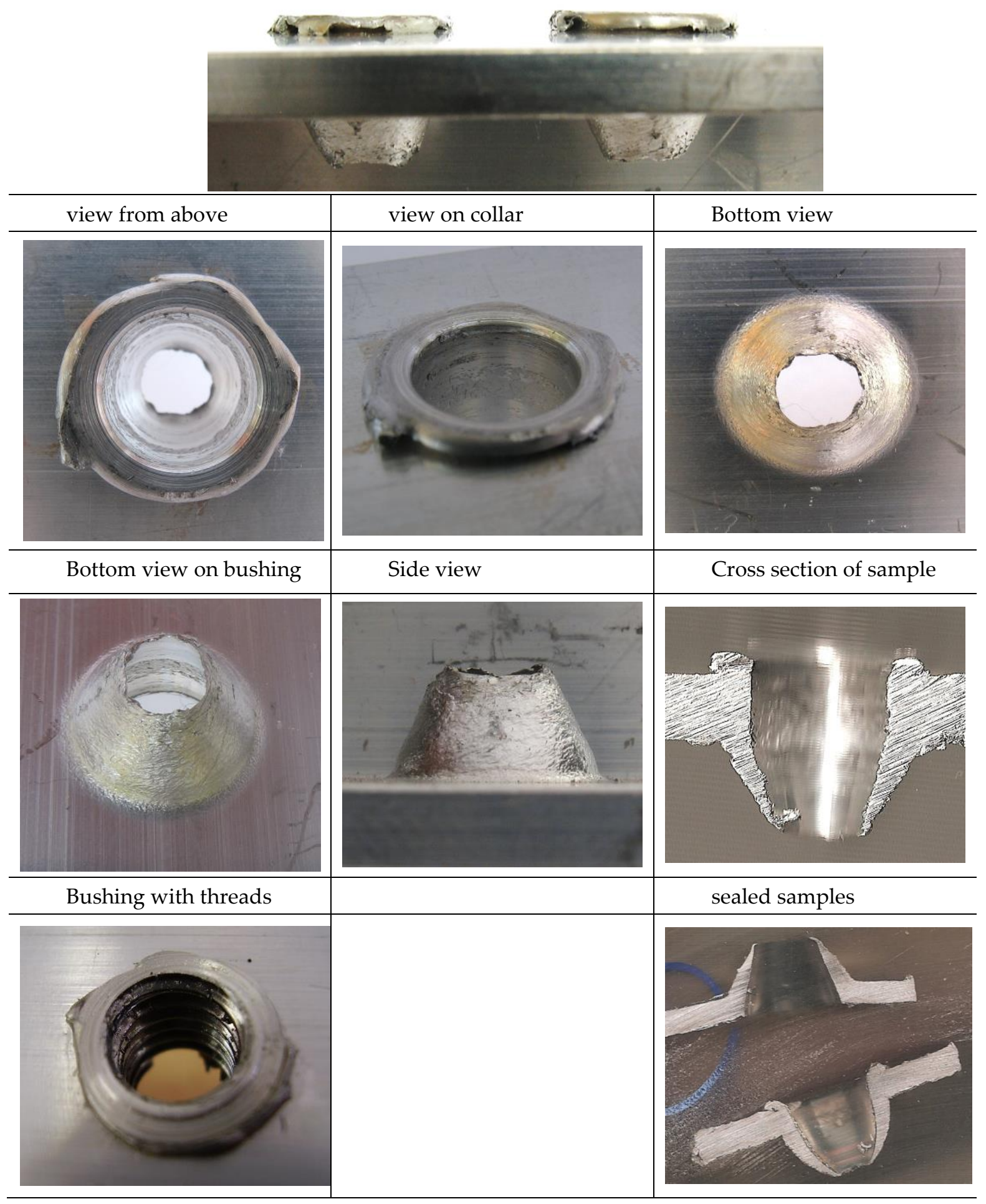

Creating of the bushings from two layers were processed, too. Visuals evaluation of collar and bushing created from two layers of material are shown in the Table 5. The testing materials were stacked on each other without pressing, only were touched in the jigs. The created bushings were without cracking, but with smaller hole in the bottom and more conical shape of bushing. After cross -cutting of testing samples, leak of material was seen between the layers of sheets. 
Table 5. Visuals evaluation of collar, bushing. Joining of bushing created from two layers of material.

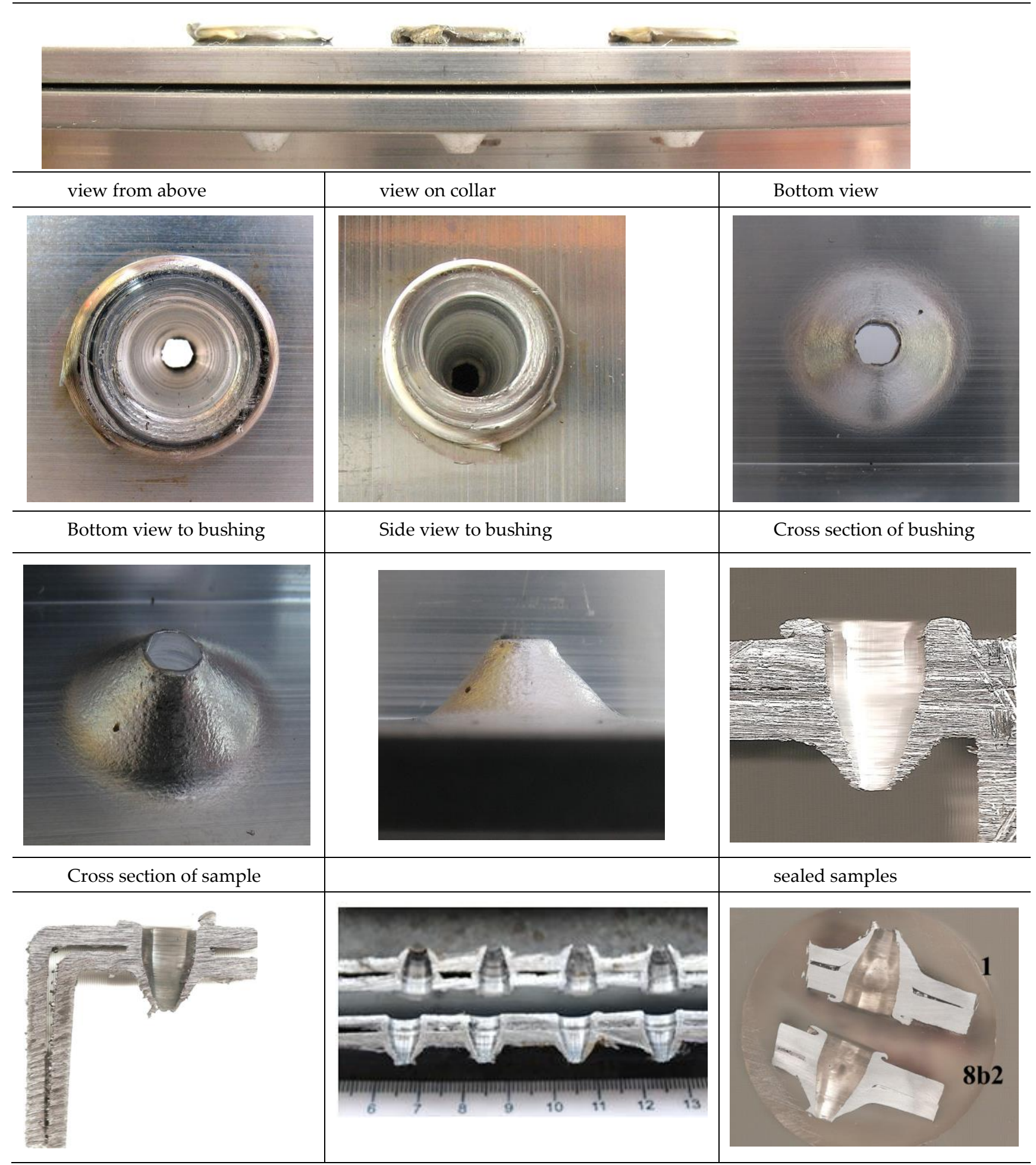

\subsubsection{Metallographic evaluation}

Metallographic evaluation consists of the evaluation of macrostructures of tested material, which was done by light microscope OLYMPUS BX FM and with digital photo apparatus OLYMPUS C - 4040. The macrostructures of prepared samples with collar, tapped threads in the cross cut bushing are shown in the Table 6. 
Table 6. Visual evaluation of macrostructure of tested sample.

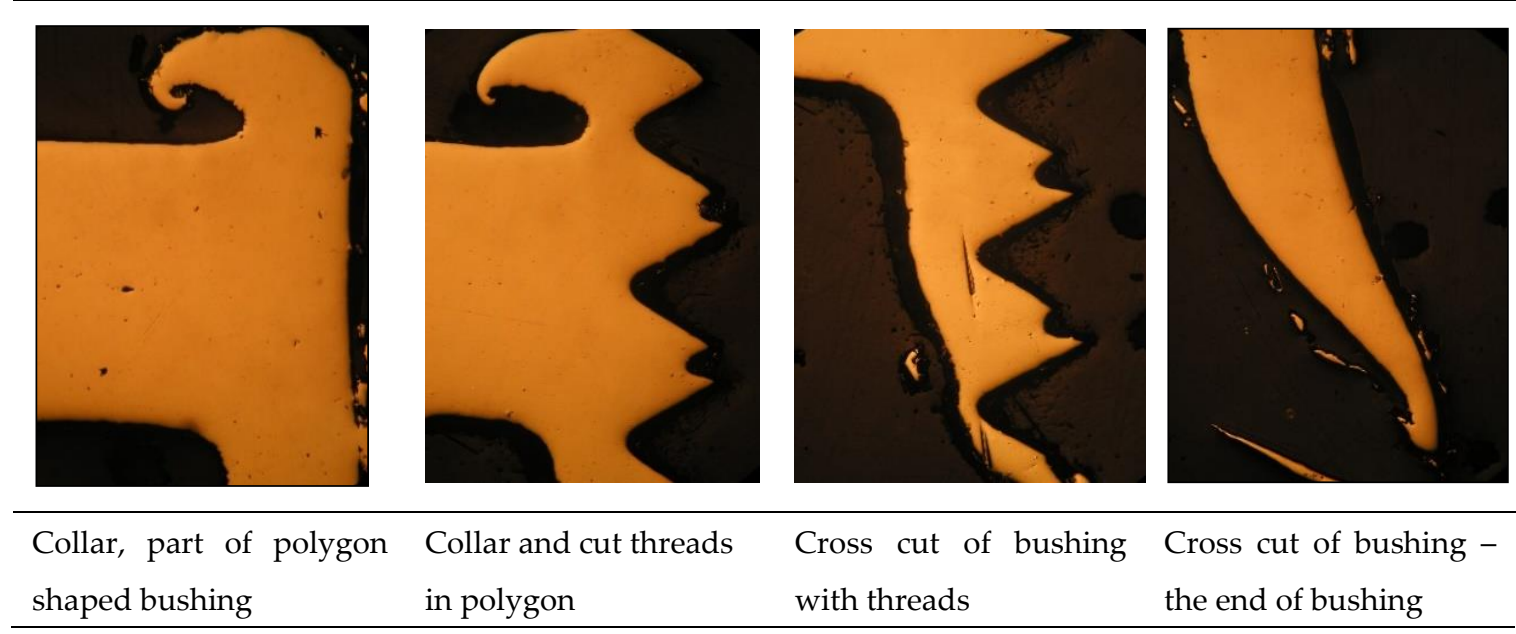

The microstructures from the thread part of bushing are shown in the Table 7 . The compressed grains are seen at the edges of the threads.

Table 7. Detail of microstructures of tapped threads.

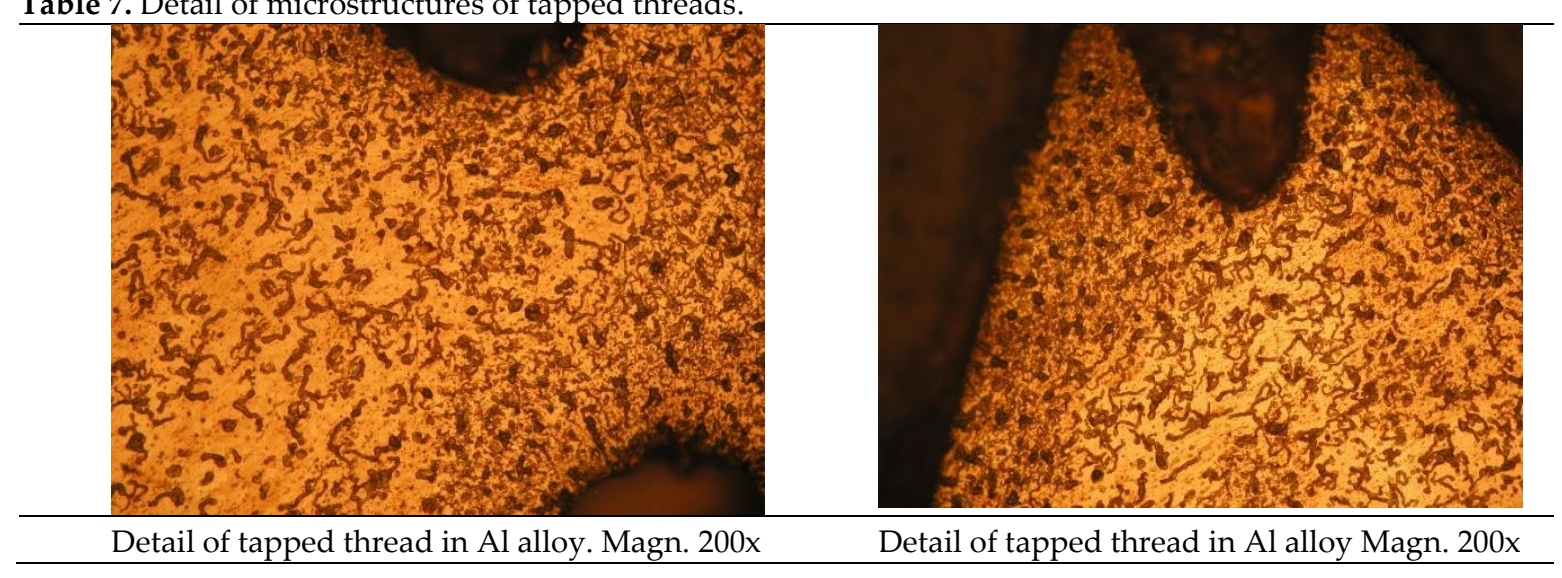

The macrostructures and detail microstructures from two layers of materials are shown in the Table 8. The images are stored sequentially from the top of the tested samples to the bottom.

The details from the left and right side of cross-cut collar are the first. Great deformation of grains is seen in the detail. The grains are deformed in the direction of flow of the material when forming the collar. The grains are most deformed in the rounded part of the collar.

Macrostructures of the bushing cut (from two layers) are shown from left and right sides. Material flow between the two layers of the laid material can be seen. The following microstructures illustrate the mixing of the material during the drilling operation and creating of bushing. The mixed materials form a permanent joint, the body of bushing.

The detail from the material joint of two materials, Fig. 3, shows the place, from which was prepared EDX analysis. The EDX analysis performed in the filling phase in Fig. 4 shows the presence of some impurities on the base of $\mathrm{Fe}, \mathrm{C}$ and $\mathrm{O}$. The microanalysis report was made from the mixed part of bushing. 
$\underline{\text { Table 8. Macrostructures and Microstructures of created collar and bushing from two layers of testing material. }}$
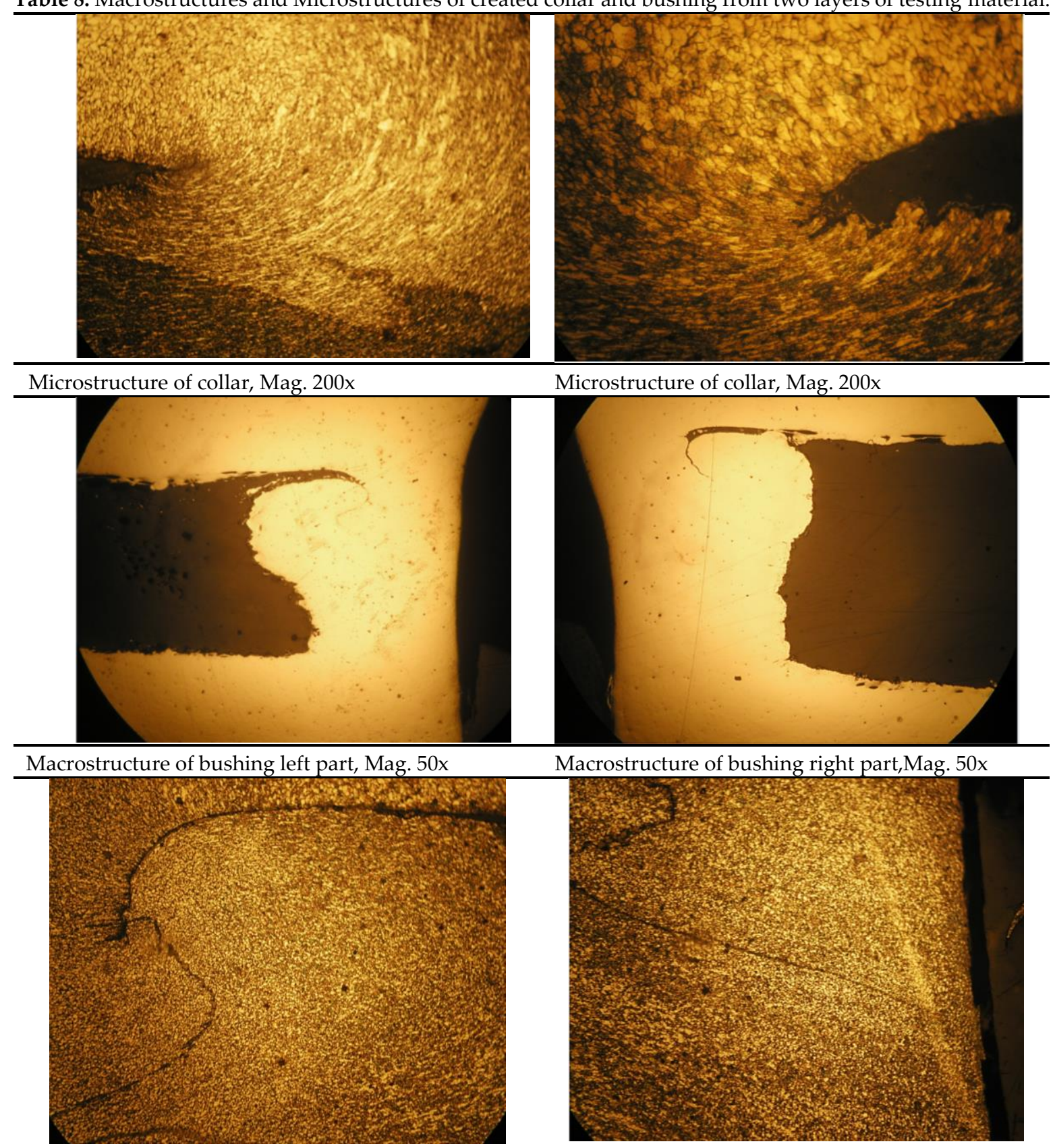

Macrostructure of bushing right part,Mag. 50x

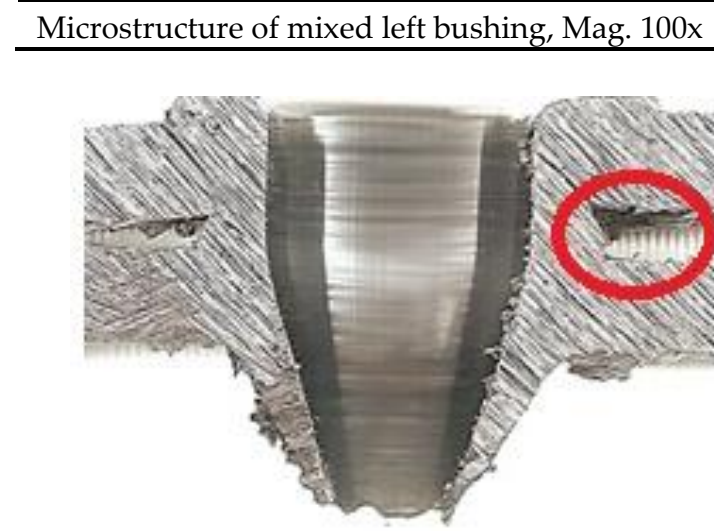

(a)

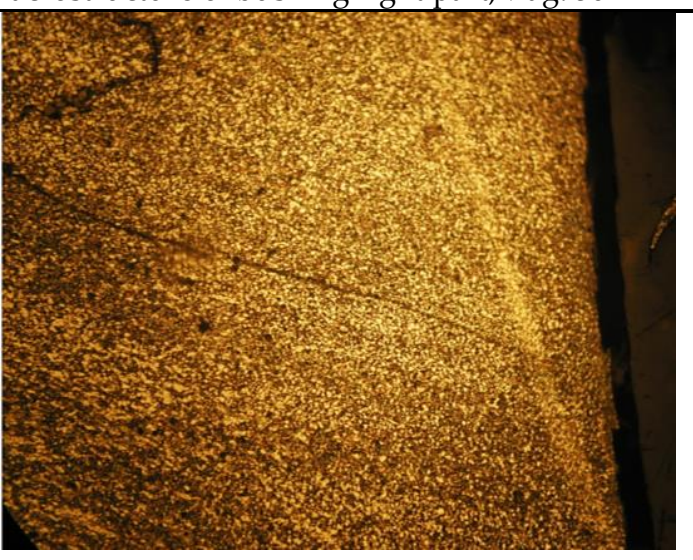

Microstructure of mixed right bushing, Mag. 100x

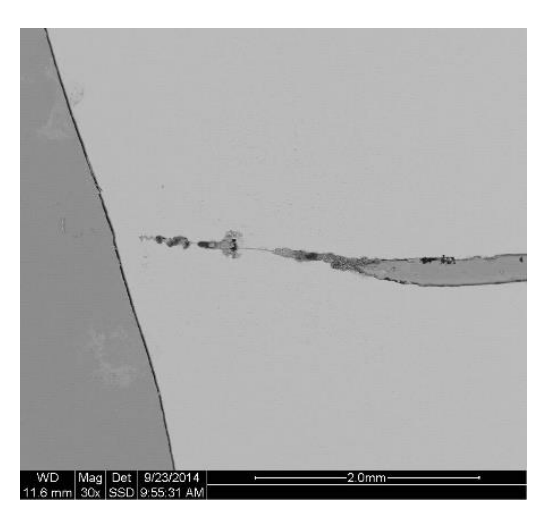

(b)

Figure 3. Place for EDX analysis: (a) mixed part, (b) end of mixed part from inside of bushing 


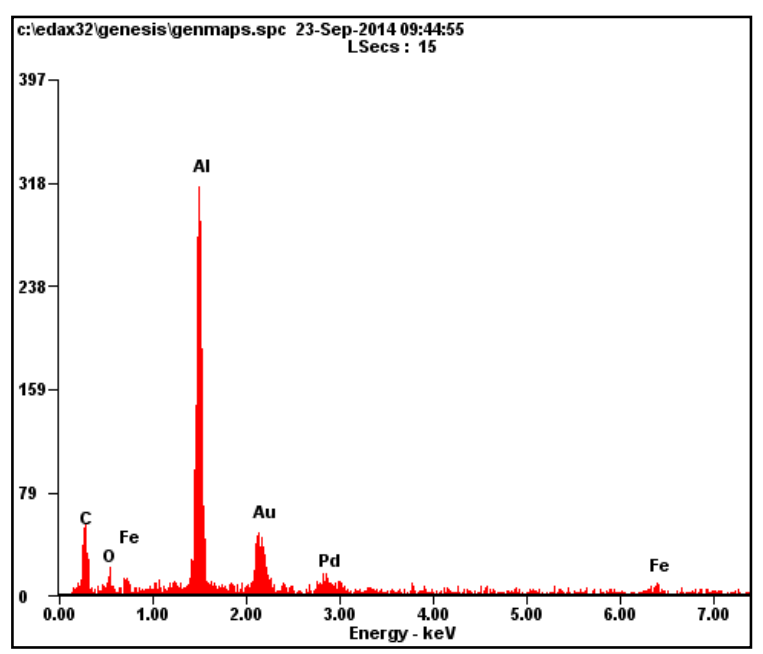

Figure 4. EDX analysis of testing Al alloy

\subsubsection{Hardness test}

The hardness Vickers test - HV was done according the standard STN ISO 6507-1 and standard ISO $6507 / 3$ in the hardness apparatus PMT -3 . The measuring places and the measuring results are shown in the Fig. 5.

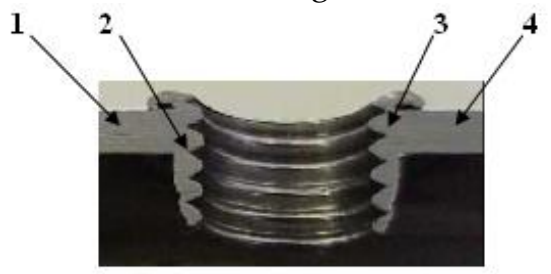

(a)

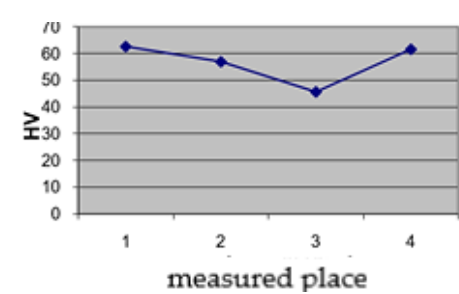

(b)

Figure 5. Micro-hardness: (a) Measuring places 1 and 4 - basic material, 2 and 3 - thread area in bushing, (b) Measured values.

The Table 9 shows the material hardness values from several test specimens (it means basic nonthermally affected material, bushing, basic non-thermally affected material). The measured results show that the basic, non-thermally affected material has higher values than the hardness values of the formed shells.

Table 9. Micro-hardness values of $\mathrm{Al}$ alloy.

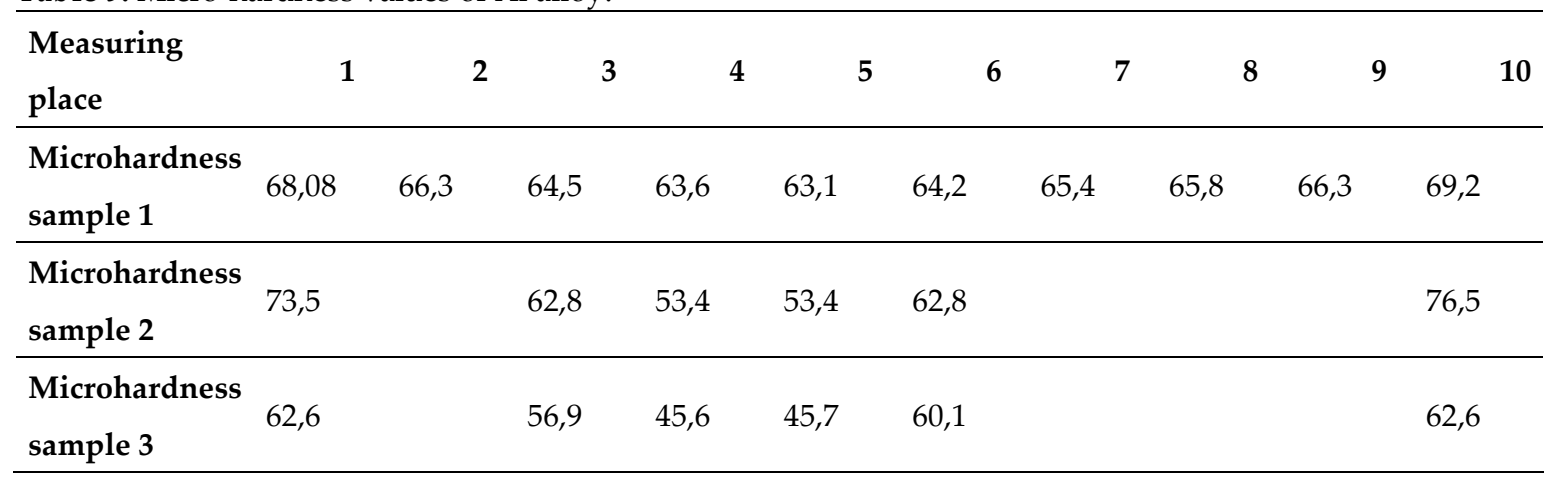

\section{Discussion}

Friction drilling process is non-conventional process of creating bushings in various types of materials and enable to create joining from one or more layers of material. The manual testing was proposed for the experiments. The quality of the created bushing depends not only on the proposed parameters and materials, but also on the researcher's skill. The quality of the bushings and collars depend not only on the proposed parameters, but also on the researcher's skill. These imperfections 
listed in Table 10 can be eliminated not only by correctly setting process parameters, but by automating of the process, where repeatability is guaranteed. The authors wanted to point out the mistakes made in the process of the production of collars and bushings. The possible errors during the creating of samples is shown in Table 10.

Table 10. The possible errors during the creating of samples is a table.

\begin{tabular}{|c|c|c|c|}
\hline Very pressed collar & $\begin{array}{l}\text { Insufficiently pressed } \\
\text { collar }\end{array}$ & $\begin{array}{l}\text { Very rough inside of the } \\
\text { bushing }\end{array}$ & $\begin{array}{l}\text { unevenly leaked edge } \\
\text { of collar }\end{array}$ \\
\hline & & $\mathrm{Ame}$ & \\
\hline $\begin{array}{l}\text { Roughened strips inside } \\
\text { the bushing }\end{array}$ & Torn end of bushing & $\begin{array}{l}\text { Scales and cracks } \\
\text { around circumference } \\
\text { of the bushing }\end{array}$ & $\begin{array}{l}\text { Scales and cracks } \\
\text { around circumference } \\
\text { of the bushing }\end{array}$ \\
\hline
\end{tabular}

\section{Conclusions}

In the contribution was presented the view of nowadays progressive technology, thermal drilling by Flowdrill, utilized at the join of various types of materials, mainly in the automobile industry and civil industry.

The presented experiments were oriented to evaluation of $\mathrm{Al}$ alloy material parameters at various technological conditions, focused on the creation of collars, bushing and threads for future possible mechanical joint.

In the frame of experiments were used $\mathrm{Al}$ alloy in the shape as square pipe and as the sheets, with thickness $2 \mathrm{~mm}$ of one sheet.

We can make a conclusion from the results of the thermal drilling Flowdrill as from the metallographic samples, that the created bushings and threads in bushings have the best shape and strength properties at the higher speeds of drilling machine. The bushings (with or without the threads) in material can elongate the joining place and the joints will become more strong and safety. Also the bushings can be utilized as the helped parts in non-demount joints.

The integrity of the collar and bushing depends on:

- the type of material, its chemical and dimensional properties,

- setting of technological parameters, 
- drilling method:

- manual drilling on a drilling machine,

- automated, machine drilling,

- skills and experience of the worker.

This chip-less technology, possibility of energy saving, low cost, simplification of technological operation and undemanding for special equipment without negative environmental impacts are important factors from the environmental side. The main advantage of the thermal drilling is:

- Reduction of the number of technological operations. Progressive thermal technology simplifies the process making of bushings and holes by one technological operation - drilling with conical tool.

- Reduction of the number of necessary equipment for manual or automated production. For example, it is not necessary to use more complicated robots for welding and precise localization of nut in the holes, just use a simple drill center.

- Use of material with various thickness and type for creating of joints from mixed materials.

- Reduce the amount of inventory of additional materials as nuts, welding electrodes, etc.

- Short production time 2-6 seconds, depending on the thickness and type of used material.

- By the creation of bushings, increase the usable thickness of material, up to three times, in comparison with the original thickness of the base material.

- Using of thermal drilling operation, reduces or even completely removes waste material from the production. Material from drilling holes is transformed into collar and bushing.

- By rolled threads in the bushing or by removal of the collar from the joining place, it increases the variability in the using of joints $[4,5,11,12,22,23]$.

Author Contributions: All authors have read and agree to the published version of the manuscript. Conceptualization, Lydia Sobotova and Miroslav Badida; methodology, Lydia Sobotova; metallography Alica Maslejova; validation, Lydia Sobotova, Miroslav Badida and Alica Maslejova; formal analysis, Lydia Sobotova.; investigation, Lydia Sobotova and Alica Maslejova; writing-original draft preparation, Lydia Sobotova.; writing - review and editing, Miroslav Badida; visualization, Lydia Sobotova; supervision, Miroslav Badida; project administration, Lydia Sobotova; funding acquisition, Miroslav Badida.

Funding: This research received no external funding.

Acknowledgments: The contribution was prepared in the frame of solving of grant scientific project KEGA 041TUKE-4/2018 Transfer of knowledge from scientific - research activities from field of products disassembly and recycling into processing of the university textbook and KEGA 045TUKE-4/2018 Transfer of the latest findings of research into processing textbook "Environmental aspects of design engineering objects -Ecodesign.

Conflicts of Interest: The authors declare no conflict of interest.

\section{References}

1. Wood, K. L. Design for assembly techniques in reverse engineering and Redesign. ASME Design Theory and Methodology. Conference, DETC/DTM-1517 Irvine, CA, August 1996, pp. 1-28.

2. Nong, N.; Keju, O.; Zhang, Y.; Qiao, Z.; Changcheng, T.; Feipeng, L. Research on press joining technology for automotive metallic sheets. Journal of materials processing technology 2003, 137, pp. 159 163.

3. Pedreschi, R. F.; Sinha, B. P.; Davies, R. Advanced connection techniques for cold - formed steel structures. Journal of Structural Engineering 1997, 123, pp. 138-144.

4. Bustilloa, A.; Urbikain, G.; Perezc, J.M.; Pereirab, O.M.; Lopez de Lacalleb, L.N. Smart optimization of a friction-drilling process based on boosting ensembles. Journal of Manufacturing Systems 2018, 48, pp. 108-121. 
5. Miller, S.F. Experimental Analysis and Numerical Modeling of the Friction Drilling Process. Thesis. Doctor of Philosophy. 2006 The University of Michigan, U.S.A., pp 126.

6. Mishra R.S.; Mahoney M.W. Friction stir welding and processing. 1st ed.; ASM International; Materials Park, OH 44073-0002, U.S.A., 2007; pp. 1- 368.

7. Honda to Release all-New Fit and Fit Hybrid in Japan - All-New Fit and Fit Hybrid Achieve ClassLeading Fuel Economy. Available online: http://world.honda.com/news/2013/4130218eng.html (25 September 2019).

8. EJOT $^{\circledR}$ - The self-piercing and extruding screw for high- strength sheet joints. Available online: www.ejot.com (14 June 2019).

9. Pereira, O.; Martín-Alfonso, J.E.; Rodríguez, A.; Calleja, A.; Fernández-Valdivielso, A.; López de Lacalle, L.N. Sustainability analysis of lubricant oils for minimum quantity lubrication based on their tribo-rheological performance. J Clean Prod. 2017,164, pp. 1419-1429.

10. Mathew, N.T.; Vijayaraghavan, L. Environmentally friendly drilling of intermetallic titanium aluminide at different aspect ratio. J Clean Prod. 2017, 141, pp.439-52.

11. Miller, S.F.; Blau, P.; Shih, A. J. Microstructural Alterations Associated with Friction Drilling of Steel, Aluminum, and Titanium, Journal materials Engineering and performance 2005, 14, pp. 647-653.

12. Miller, S.F.; Wang, H.; Li, R.; Shih, A.J. Experimental and numerical analysis of the friction drilling process, ASME Journal of Manufacturing Science and Engineering 2006, 128, pp. 803-810.

13. Pantawane, P.D.; Ahuja, B.B. Experimental investigations and multi-objective optimization of friction drilling process on AISI 1015, International Journal of Applied Engineering Research, Dindigul 2011, 2, pp. 448-461.

14. Ahn, D.G.; Jung, G.W. Influence of process parameters on drilling characteristics of $\mathrm{Al} 1050$ sheet with thickness of $0.2 \mathrm{~mm}$ using pulsed Nd:YAG laser. Trans. Nonferrous Met. Soc. China 2009, 19, pp. 157163.

15. Miller, S.F.; Shih, A.J. Thermo-Mechanical Finite Element Modeling of the Friction Drilling. Journal of Manufacturing Science and Engineering 2007, 129, pp. 531-538.

16. Padma Raju, B.; Kumara Swamy, M. Finite Element Simulation of a Friction Drilling process using Deform-3D. International Journal of Engineering Research and Applications (IJERA) 2012, 2, pp. 716 -721.

17. Miller, S.F.; Tao, J.; Shih, A.J. Friction drilling of cast metals, International Journal of Machine Tools and Manufacture 2006, 46, pp. 1526-1535.

18. Miller, S.F.; Shih, A.J. Tool wear in friction drilling, International Journal of Machine Tools and Manufacture 2007, 47, pp. 1636-1645.

19. Cebeli, O, Zulkuf, D. Investigate the Friction Drilling of Aluminium Alloys According to the Thermal Conductivity. TEM Journal 2013, 2, pp. 93 - 101.

20. Formdrill. Available online: http://www.formdrill.eu, (15 September, 2019).

21. Eliseeva, A. A.; Fortunaa, S.V.; Kolubaeva b, E.A.; Kalashnikova, T. A. Microstructure modification of 2024 aluminum alloy produced by friction drilling. Materials Science E Engineering A 2017, 691, pp. 121125.

22. Flowdrill- Metallurgical Laboratory Report. April 2005. Available online: E: $\backslash$ FLOWDRILL WORKSHOP $\backslash$ INTERNATIONAL $\backslash$ REPORTS $\backslash$ Metallurgical Laboratory Report_eng.doc (5 May 2009)

23. Urbikain, G.; Perez, J. M. ; Lopez de Lacalle, L.N. ; Andueza, A. Combination of friction drilling and form tapping processes on dissimilar materials for making nutless joints. J Engineering Manufacture 2016, 232, pp. 1007-1020.

24. Matysiak, W.; Bernat L. Shaping the edges using Flowdrill technology. METALURGIJA 2015,54, pp. 235-238.

25. Folea, M.; Schlegel, D.; Gete, E.; Langlade, C. ; Roman, A. Preliminary tests on flowdrilling of maraging steels. Academic Journal of Manufacturing Engineering 2012, 10, pp. 42 - 47. 